\title{
Discussion Paper No. 14-022 \\ Efficient Contracts for Government Intervention in Promoting Next Generation Communications Networks
}

Wolfgang Briglauer and Christian Holzleitner

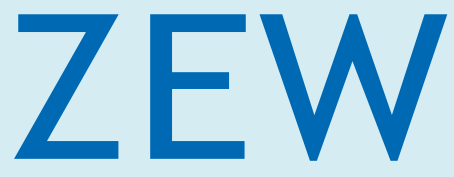

Zentrum für Europäische Wirtschaftsforschung $\mathrm{GmbH}$

Centre for European

Economic Research 
Discussion Paper No. 14-022

\section{Efficient Contracts for Government Intervention in Promoting Next Generation Communications Networks}

Wolfgang Briglauer and Christian Holzleitner

Download this ZEW Discussion Paper from our ftp server:

http://ftp.zew.de/pub/zew-docs/dp/dp14022.pdf

Die Discussion Papers dienen einer möglichst schnellen Verbreitung von neueren Forschungsarbeiten des ZEW. Die Beiträge liegen in alleiniger Verantwortung der Autoren und stellen nicht notwendigerweise die Meinung des ZEW dar.

Discussion Papers are intended to make results of ZEW research promptly available to other economists in order to encourage discussion and suggestions for revisions. The authors are solely responsible for the contents which do not necessarily represent the opinion of the ZEW. 


\title{
Efficient contracts for government intervention in promoting next generation communications networks
}

\author{
Wolfgang Briglauera \\ Christian Holzleitnerb
}

March 2014

\begin{abstract}
Although the future socio-economic benefits of a new fibre-based ("next generation access", NGA) telecommunications infrastructure seem to be uncontroversial, a universal NGA coverage appears to be a rather unrealistic objective without government intervention. We contend, however, that the current contract practice of fixing ex ante targets for network expansion is inefficient given the uncertainty about future returns on NGA infrastructure-based services and the public authorities' incomplete information about the capital costs of the network provider. This paper puts forward to delegate the choice of the network expansion to the NGA provider.
\end{abstract}

Keywords: Contract theory, public utilities, next generation telecommunications networks, subsidies

JEL: H20, L43, L44, L51, L52, L96

a (Corresponding author) Wolfgang Briglauer, Centre for European Economic Research (ZEW Mannheim), e-mail: briglauer@zew.de, phone: +49 (o) 621 1235-279, fax: +49 (o) 621 1235-170. P.0. Box 103443, 68034 Mannheim, Germany.

b Christian Holzleitner, DG Climate Action, European Commission, e-mail: cholzleitner63@gmail.com, phone: +32 (o) 229964 52. Office BU24 1/71, B-1000 Brussels, Belgium. The views expressed are entirely those of the author and do not represent those of the European Commission. 


\section{Introduction}

The deployment of fibre-based next-generation access (NGA) telecommunications networks has become a major challenge for sector-specific regulators, governments and network providers in recent years. Traditional (first-generation copper-based) telecommunications networks seem to be outdated and it has become necessary to speed up these networks to account for the growing demand for bandwidth. Such needs come from new and interactive services such as file sharing and streaming, highquality video conferencing, cloud computing, teleworking, distance learning, telemedicine and so on. The future importance of ultra-high speed broadband infrastructure is largely undisputed and mainly related to the potential of significant productivity improvements and economic growth across all business sectors. ${ }^{1}$ However, replacing existing telecommunications networks with fibre optic networks requires massive investment volumes. These are of much greater magnitude than the previous investments required for upgrading first-generation copper networks to facilitate broadband services and add up to billions of Euros for nationwide (second-generation) NGA deployment. ${ }^{2}$

1 For empirical evidence, see Röller and Waverman (2001) who investigate the impact of traditional telecommunications infrastructure on economic growth, Garbacz and Thompson (2007) for the impact of Internet services and information networks on productive efficiency and Czernich et al. (2011) for the impact of high-speed broadband networks on economic growth. OECD (2009) also estimates the positive spillover effects of high-speed broadband infrastructure on other business sectors.

2 Cost estimates for $100 \%$ coverage in all member states of the European Union (EU) vary between $€ 192$ billion and $€ 280$ billion (FTTH Council Europe, 2012a, p. 10). 
As private investors are apparently not ready to roll out NGA networks in remote (unprofitable or "white") 3 regions but only in densely populated areas, it seems that public subsidies are needed to achieve universal NGA deployment. Indeed, in Asian countries (such as South Korea and Japan) and northern European countries (such as Denmark, Norway and Sweden), national governments in the early nineties initiated broadband strategies as a complementary measure to market liberalization and sectorspecific regulation. In particular, the Asian countries that have provided the highest public subsidies for NGA deployment (see Table 1 in section 2.3) are heading the broadband as well as high-speed (fibre-based) broadband rankings by a large margin today (FTTH Council Europe, 2012b).

A growing branch of the literature focuses on different aspects of the funding of NGA networks. Diverse funding instruments and cost models have been discussed and developed by industry consultants (e.g. Neumann, 2010; wik consult, 2008; dot.econ, 2012; Ventura Team \& Portland Advisers, 2012), international organizations (e.g. OECD, 2008, 2009; ITU, 2009) and in the policy-oriented work of academics (e.g. Huigen \& Cave, 2008; Cave \& Martin, 2010; Falch \& Henten, 2010) in recent years. Belloc et al. (2012) are the first to examine econometrically the distinct effects of demand- and supply-side policies on the diffusion of conventional broadband technologies. They

3 The European Commission (2009, para 40) "made a distinction between areas where no broadband infrastructure exists or is unlikely to be developed in the near term (white areas), areas where only one broadband network operator is present (grey areas) and areas where at least two or more broadband network providers are present (black areas)." 
find that although both kinds of funding policies have a positive impact on broadband diffusion, their effectiveness is dependent on the respective diffusion stage. Jullien et al. (2010) is a theoretical paper that analyzes the interaction between regulators, incumbents and local governments with regard to investment in new network infrastructure. They find that government intervention can be welfare reducing in the case of asymmetric information or regional externalities. In addition to this more applied research, a rich literature exists on the general theory of public intervention under uncertainty. It is developed how a public authority must design optimal contracts under incomplete information about costs and demand (see e.g. Laffont \& Tirole, 1993, for a seminal theory of incentive regulation under asymmetric information, Armstrong \& Sappington, 2006, 2007, for comprehensive reviews of regulatory theory and Holzleitner, 2001, for an assessment of regulatory contracts in practice). There is also a growing literature on public-private partnerships (PPPs) related to this paper (see Engel et al. (2013) and the literature cited therein). A primary focus of this literature is on the allocation of risks between the public authority and private provider. Engel et al. (2001) derive the optimal length of concessionaire contracts under uncertain demand. Martimort and Pouyet (2008) and lossa and Martimort (2008) study the optimal bundling of tasks (e.g. network construction and its operation) in a moral hazard model. Engel et al. (2013) investigate the optimal choice between financing through user revenue and public subsidies under demand uncertainty.

According to the best of our knowledge, there has been no systematic attempt at combining these branches of the literature in terms of evaluating the real-world public 
funding of NGA deployment in light of information asymmetries and efficiency considerations. Given the economic and social desirability of universal NGA deployment and insufficient private investment, we want to examine the following research question: Is the current practice of funding NGA rollout projects efficient, and, if not, how can public authorities despite their informational disadvantages design simple and robust contracts that provide more efficiency-based incentives for increased NGA deployment but nevertheless minimize public expenditure? Our main proposition is that the level of network expansion or of other quality criteria should not be fixed ex ante by the public authority but that this choice should be left to the NGA provider who has better knowledge of investment costs. Furthermore, we show that such contracts can be readily implemented based on existing accounting data and that it is not necessary to undertake any additional verification of cost or demand data. Finally, as we directly solve for the optimal contract, the trade-off between incentives for network expansion and the limitation of the NGA provider's profit can be explained in a more accessible way to policymakers.

The remainder of this paper is organized as follows. Section 2 briefly provides the necessary background on the technical context and then outlines the basic economic rationale for NGA-related subsidies. This is supplemented by a compilation of representative funding practices in countries leading in fibre deployment and/or most engaged in public subsidy programmes. Section 3 presents a formal model with optimal linear contracts for principal/agent settings with complete and incomplete information. As this paper aims specifically to take account of the real-world 
characteristics of NGA deployment, section 4 compiles the relevant policy implications that directly follow from the main results of our model. Section 5 contains some further relevant policy considerations and, finally, section 6 summarizes and contains some qualifying remarks.

\section{Institutional framework and evidence}

\subsection{Basic technological concepts and definitions of NGA scenarios}

First-generation communications networks provide broadband services by means of the $x D S L$ transmission technology that allows a connection speed in the range of 256 $\mathrm{kbit} / \mathrm{s}$ to $20 \mathrm{Mbit} / \mathrm{s}$. In order to further increase the current bandwidth and to fulfil future broadband demand, it is necessary to shorten the length of the local copper-wire loops. As a first solution, where a DSL transmission system is deployed in cabinets, the connection to the backbone network can be replaced by means of optical fibre. In the remaining copper-wire lines, the latest DSL transmission technology is used. This solution ("fibre to the curb/cabinet", FTTC) can provide bandwidths of approximately $20 \mathrm{Mbit} / \mathrm{s}$ to $100 \mathrm{Mbit} / \mathrm{s}$ depending on the length of the remaining copper lines. Second, higher bandwidths (above $100 \mathrm{Mbit} / \mathrm{s}$ ) will be achieved if the final copper-wire line is shortened further. Fibre to the building (FTTB) is an implementation scenario in which optical fibre is extended to or into the building. Third, if it feasible to also renew or replace in-house wiring, it is possible to eliminate copper lines entirely. In such a 
scenario, the optical line is directly connected to the individual apartment or home ("fibre to the home", FTTH).4

\subsection{The economic rationale for subsidizing NGA deployment}

NGA deployment causes high construction costs related to civil work for digging, inhouse wiring and laying down optical cables, which are literally sunk and account for $60 \%$ to $80 \%$ of the NGA network's total costs (ERG, 2007, pp. 16-17), followed by duct costs and fibreglass. Since access networks branch out in a tree-like structure as they approach the final consumer, renewing line infrastructure involves fewer customers the closer one gets to the final consumer. This means that rollout costs will be distributed among fewer customers and average cost per customer will be higher. In many cases, access networks therefore represent "natural monopolies", where economies of scale in terms of density make it much less expensive to integrate additional customers into an existing network than to provide them with separate (parallel) networks (RTR, 2010, p. 192).

In particular, high investment volumes come along with distinctive risks of NGA deployment. Next to the risks that arise from the sunk cost nature of NGA investment, potential investors face the following risks, which all influence investment decisions in

4 For the different NGA scenarios, see RTR (2010, pp. 189-191) and Briglauer et al. (2013, p. 3). In addition, cable television and mobile (wireless) networks might also be used to roll out high-speed communications networks. Cable and FTTC networks represent hybrid access network technologies combining existing and new infrastructure that may be sufficient to meet bandwidth demand at least in the mid-term. 
a negative way: the long amortization periods (20-25 years) of network infrastructure, the technical risk of the new technology as well as substantial uncertainties regarding future demand for new high-speed broadband services. The expected value of those uncertain revenues may not be sufficient to render profitable an investment into a nationwide NGA network. Furthermore, NGA investors are confronted with regulatory risks because the set of ex ante NGA specific regulations is still an open issue in most countries. 5 NGA investors may fear that regulators will be subject to moral hazard and take away realized profits if business turns out better than initially expected. Of course, this creates another source of uncertainty, especially for operators who most likely will be deemed as dominant and therefore subjected to sector-specific regulation in future decisions.

Given the economics and specific risks of NGA deployment, it is unlikely that private investment will be induced by competition or sector-specific regulation on a broad or even nationwide scale. ${ }^{6}$ However, aggregate societal benefits may exceed private willingness to pay, which then creates a case for public intervention. As 100 years ago

5 For a recent overview of the regulatory status, see wik consult (2012).

6 The impact of regulation is actually greatly disputed in the academic literature. The vast majority of the related literature indicates a negative net impact of regulation on investment in general and broadband, in particular (see Cambini \& Jiang (2009), who review the relevant empirical and theoretical work). Briglauer et al. (2013) and Briglauer (2014), who empirically examine the determinants of NGA investment and adoption, respectively, also find that service-based competition in terms of broadband access regulations has a negative impact on both NGA investment and adoption. 
with the rollout of first-generation networks, additional public subsidy programmes seem to be necessary to realize the positive externalities of communications networks (e.g. increasing efficiency and decreasing costs in other business sectors). 7 In addition, national governments and local municipalities consider high-speed broadband infrastructure to be a necessity to increase the competitiveness of their countries and regions and to attract international business (Falch \& Henten 2010, p. 2). Finally, owing to the economies of density, public subsidies will be particularly important for white areas where NGA provision is unprofitable. For such - mainly rural - areas, public subsidies are also to be expected, because otherwise a politically unacceptable gap to urban areas ("digital divide") would increase. Overall, the economic rationales for subsidizing NGA deployment projects rest upon market structural characteristics, macroeconomic reasoning ${ }^{8}$ and equity motives and, thus, intervention is covered by mainstream economics (Gomez-Barroso \& Feijob, 2010, pp. 488-490).

7 OECD (2009) calculates that even slight spillover effects that accrue in major sectors of the economy such as health, transport or energy are sufficient for justifying subsidies for nationwide NGA deployment.

8 The recent economic downturn provided another good reason for national governments to consider public subsidies for NGA networks. On one hand, the crisis impinges upon private investment decisions and diminishes access to private capital; on the other hand, NGA deployment constitutes innovative and reasonable investment options for governments (Bauer, 2010, p. 72). 
Public subsidies can be targeted towards either the demand or the supply side. 9 Direct supply-side stimuli not only include non-refundable public funds or facilitated loans but also PPPs, where national governments play a coordination and partial financing role and where both types of partners contribute with certain comparative advantages. Cooperating partners are usually telecommunications providers (across the value chain), other public utilities (most notably, energy utilities), real estate developers and public entities (municipalities, local authorities, the state). PPPs seem to be especially attractive for the rollout of NGA networks, which require investments that are normally beyond the scope of public subsidizing, as they would lead to sharing investment risks among the partners involved (Cave \& Martin, 2010, p. 3). PPPs can be implemented by means of a purely contractual basis or by creating a new legal entity (Falch \& Henten, 2010 , p. 2). The most interventionist form of public funding is in terms of direct infrastructural investment where the government owns parts of or the entire NGA network.

\subsection{Previous NGA funding practice}

Table 1 provides an overview of the major NGA subsidy programmes with countryspecific information in columns 2 and 3 . The focus is on some of the most prominent and far-reaching subsidy programmes in Asia, the US and some of the fibre-leading

9 Demand stimuli are not considered in the remainder of this paper, although they might be an important complementary instrument, but yet far from sufficient given the massive investments required for a broad scale NGA rollout. According to Belloc et al. (2012), demand-side stimuli become favourable at more advanced stages of the diffusion process. 
European countries. ${ }^{10}$ Column 1 contains a selection of countries ${ }^{11}$ with $\mathrm{FTTH} / \mathrm{B}$ household penetration rates of $>5 \%$ as of December 2011 (ranks in parentheses). ${ }^{12}$ Table 1 also includes the EU, which is the only multinational entity with its own funding activities so far, as well as countries with low current FTTH/B penetration but with most ambitious public subsidy programmes in per capita terms (AU and NZ). Table 1, however, excludes some high-ranked countries where there are either no major NGA public funding projects known or data are not available. ${ }^{13}$

From Table 1, we infer that in several of the leading FTTH/B countries, major public subsidies are already in place. Although volumes of public subsidies vary widely among countries as regards absolute size, institutional design and temporal allocation, they are, by all means, substantial in their total scope. When looking at the EU as a whole, the European Commission approved $€ 3.3$ billion of public funds spent by member states for high-speed broadband development projects from 2003 to 2010 . In

10 These regions clearly represent the global "NGA hotspots" with 49.5 million FTTH/B subscribers in Asia, 10.2 million subscribers in Europe (including Russia) and 7.3 million subscribers in the US. The other regions represent fewer than 1 million FTTH/B subscribers (FTTH Council Europe, 2012b).

11 The two-letter country codes (CC) in column 1 (and below) follow the ISO standard.

12 Source: FTTH Council Europe (2012b).

13 Some of the most advanced fibre nations such as AE $(55 \% /(2))$ and TW $(29 \% /(5))$ have also experienced massive public NGA rollout programmes but no information is available for the purposes of comparison in Table 1. Among the global FTTH/B frontrunners, only a few nations such as HK $(45.5 \% /(3))$ as well as a couple of Eastern European countries have shown massive growth without any forms of (substantial) public funding initiatives. 
addition, the European Commission granted an additional $€ 2.3$ billion out of its own funds from 2007 to 2010 . The majority of these projects have been undertaken in the form of PPPs to focus financial resources and to share risk. However, any public financing of such projects must be in line with the EU principles of state aid control as well as the specific broadband/NGA state aid guidelines (European Commission, 2009, 2012). Compliance with those rules ensures that public funding does not lead to an overcompensation of the NGA provider, while equal access to the network is ensured for competitors.

In order to limit the profits of subsidized NGA providers, public authorities use different approaches. They may create competition upfront by making the public funding subject to a competitive tendering process and/or impose an upper limit on realized profit. According to EU state aid rules (European Commission, 2013, para 79 I; European Commission, 2009, para $51 \mathrm{~h}$ ), when public authorities use a claw-back rule on realized profit, the NGA provider is only allowed to earn an average industry profit. Any realized profit that goes beyond that benchmark has to be paid back. ${ }^{14}$

14 See e.g. European Commission (2010c, para 38) on the monitoring and claw-back mechanism for state aid to the German framework programme on duct support. In order to prevent the chosen operators from obtaining an unreasonable profit in relation to the state support, the awarding authority examines as a rule after five years whether demand for broadband services in the subsidized area grew beyond the estimates given in the operator's bid. If there is an increase of demand of more than $30 \%$, the operator will calculate the respective turnover exceeding that $30 \%$. Any profit calculated on that turnover will be reimbursed to the awarding authority. Similarly, see European Commission (2010d, para 27) on the claw-back mechanism for state aid to next-generation 
In all of the countries listed in Table 1, public subsidy programmes typically specify quality characteristics in terms of bandwidth that has to be reached for a certain percentage of the population (households) within a predefined timeframe. Quality characteristics and deployment costs are always subject to some kind of contract between funding and operating entities, irrespective of the type of public funding programme at hand. In addition, in most cases public funding is to a greater or lesser extent directly linked to close supply gaps in white areas. Exceptions (such as SG) are very few and due to country-specific demographic and topographic conditions.

Finally, it is noteworthy that the NGA subsidies - and the related PPPs - are often managed by public authorities at the regional or local level. While the national sectorspecific telecommunications regulator is inter alia responsible for setting the level of access charges, NGA subsidies are implemented by regional or local governments. With regard to the design of PPPs, it is generally the case that the private provider constructs, owns and operates the NGA network. The ownership and network operations are therefore bundled with the private provider.

broadband in North Yorkshire. The preferred bidder will pay back part of the state aid to the UK authorities if demand for broadband in the target area grows beyond anticipated levels and this leads to a situation where the support granted is deemed to be higher than the average of the industry during the lifetime of the project. Any extra profit will be calculated annually and, at the end of the lifetime of the project, the cumulative calculation will determine the amount of the funding to be paid back. 
Table 1: NGA-specific subsidies and FTTH/B household penetration (selected countries)

\begin{tabular}{|c|c|c|}
\hline $\begin{array}{l}\text { CC } \\
\% \\
\text { (Rank) }\end{array}$ & $\begin{array}{l}\text { Description } \\
\text { Type of programme } \& \text { costs }\end{array}$ & $\begin{array}{l}\text { Specification } \\
\text { Quality characteristics \& targets }\end{array}$ \\
\hline $\begin{array}{l}\text { KR } \\
57.8 \\
(1)\end{array}$ & $\begin{array}{l}\text { Government builds an ultra-broadband } \\
\text { convergence network in combination with PPPs } \\
\text { Total costs: } € 17 \mathrm{~b} \\
\text { Public subsidies: } €_{1} \mathrm{~b}\end{array}$ & $\begin{array}{l}100 \mathrm{Mbit} / \mathrm{s} \text { for } 14 \text { million users until 2012; } \\
\text { starting in } 2012 \text {, government builds Gbit/s } \\
\text { networks in big cities } \\
\text { Time frame: } 2009-2013 \\
\text { White areas: yes }\end{array}$ \\
\hline $\begin{array}{l}J P \\
45 \cdot 5 \\
(4)\end{array}$ & $\begin{array}{l}\text { Broadband network funded by the government, } \\
\text { but constructed by a private company in } \\
\text { conjunction with a tender } \\
\text { Total costs: } € 59 \text { b (full coverage) } \\
\text { Public subsidies: } € 1.73 \text { b }\end{array}$ & $\begin{array}{l}\text { FTTH/B high-speed broadband with } 90 \% \\
\text { coverage in } 2010 \\
\text { Time frame: } 2009-2010 \\
\text { White areas: yes }\end{array}$ \\
\hline $\begin{array}{l}S G \\
8.1 \\
(14)\end{array}$ & $\begin{array}{l}\text { Government establishes two vertically } \\
\text { separated operating companies in connection } \\
\text { with a public tender } \\
\text { Total costs: no estimates } \\
\text { Public subsidies: } € 0,55 \mathrm{~b}\end{array}$ & $\begin{array}{l}95 \% \text { coverage of households and offices until } \\
2012 \text {; national broadband network should } \\
\text { deploy FTTH to } 100 \% \text { of homes } \\
\text { Time frame: } 2009-2013 \\
\text { White areas: no }\end{array}$ \\
\hline \multirow[t]{2}{*}{$\begin{array}{l}\text { US } \\
8.3 \\
(13)\end{array}$} & $\begin{array}{l}\text { Programme to promote universal broadband } \\
\text { access by means of the direct funding of } \\
\text { individual projects based on a tender } \\
\text { Total costs: no estimates } \\
\text { Public subsidies: } €_{5} \mathrm{~b}\end{array}$ & $\begin{array}{l}\text { Different NGA technologies; } 100 \mathrm{Mbit} / \mathrm{s} \text { for } \\
100 \text { million users and at least one } \mathrm{Gbit} / \mathrm{s} \\
\text { connection to every municipality until } 2020 \\
\text { Time frame: } 2010-2020 \\
\text { White areas: yes }\end{array}$ \\
\hline & \multicolumn{2}{|c|}{ Source (KR; JP; SG; US): Doose et al. (2009, pp. 14-33, 27-29, 58) } \\
\hline $\begin{array}{l}\text { EE } \\
7.1 \\
(17)\end{array}$ & $\begin{array}{l}\text { Government plans to construct a nationwide } \\
\text { high-speed broadband network within a PPP } \\
\text { Total costs: no estimates } \\
\text { Public subsidies: } € 0.06 \text { b }\end{array}$ & $\begin{array}{l}\text { Provision of } 100 \mathrm{Mbit} / \mathrm{s} \text { coverage to } 90 \% \text { of } \\
\text { the population by } 2012 \text {, with the remainder } \\
\text { to be connected by } 2015 \\
\text { Time frame: } 2009-2016 \\
\text { White areas: yes }\end{array}$ \\
\hline $\begin{array}{l}\text { SE } \\
13.6 \\
(8)\end{array}$ & $\begin{array}{l}\text { Local governmental initiatives in deploying } \\
\text { wholesale infrastructure in connection with } \\
\text { municipality-owned utilities } \\
\text { Total costs: no estimates } \\
\text { Public subsidies: } € 0.24 \mathrm{~b}\end{array}$ & $\begin{array}{l}\text { FTTH, } 100 \text { Mbit/s with } 40 \% \text { coverage until } \\
\text { 2015; } 90 \% \text { coverage until } 2020 \\
\text { Time frame: } 2010-2020 \\
\text { White areas: yes }\end{array}$ \\
\hline $\begin{array}{l}S L \\
9.7 \\
(10)\end{array}$ & $\begin{array}{l}\text { Public investment funds cover about } 30 \% \\
\text { within PPPs based on a public tender } \\
\text { Total costs: no estimates } \\
\text { Public subsidies: } € 0.04 \mathrm{~b}\end{array}$ & $\begin{array}{l}\text { To provide FTTH access in white spots } \\
\text { Time frame: } 2008 \text { to ongoing } \\
\text { White areas: yes }\end{array}$ \\
\hline \multirow[t]{2}{*}{$\begin{array}{l}\text { PT } \\
6.5 \\
(18)\end{array}$} & $\begin{array}{l}\text { Government provides line of credit, private } \\
\text { partners are cooperating via PPPs } \\
\text { Total costs: no estimates } \\
\text { Public subsidies: } € 0.8 \mathrm{~b}\end{array}$ & $\begin{array}{l}\text { To provide } 50 \% \text { population coverage via } \\
\text { FTTH/C } \\
\text { Time frame: } 2009-2029 \\
\text { White areas: yes }\end{array}$ \\
\hline & \multicolumn{2}{|c|}{ Source (SE; SL; EE): Analysys Mason (2010), Falch \& Henten (2010) } \\
\hline EU & Public funding of individual projects subject to & Digital Agenda for Europe: $30 \mathrm{Mbit} / \mathrm{s}$ for \\
\hline
\end{tabular}




\begin{tabular}{|c|c|c|}
\hline & $\begin{array}{l}\text { broadband/NGA state aid guidelines } \\
\text { Public subsidies by EU member states: } €_{3.3} \mathrm{~b} \\
\text { EU structural funds: } € 2.3 \mathrm{~b}\end{array}$ & $\begin{array}{l}100 \% \text { of households and } 100 \mathrm{Mbit} / \mathrm{s} \text { for } 50 \% \\
\text { Time frame: } 2010-2020 \\
\text { White areas: yes }\end{array}$ \\
\hline & \multicolumn{2}{|l|}{ Source: European Commission (2009, 2010a, 2011) } \\
\hline $\begin{array}{l}\text { AU } \\
\ll 55\end{array}$ & $\begin{array}{l}\text { Government establishes new corporation, } \\
\text { holds majority of shares during construction; } \\
\text { vertical separation and PPP } \\
\text { Total costs: } € 28.9 \mathrm{~b} \\
\text { Public subsidies: (at least) } 50 \%\end{array}$ & $\begin{array}{l}\text { Up to } 100 \mathrm{Mbit} / \mathrm{s} \text { for } 90-93 \% \text { of fibre to } \\
\text { homes, workplaces and schools by } 2018 \text {; } \\
\text { wireless for remaining } 7-10 \% \text { with } 12 \mathrm{Mbit} / \mathrm{s} \\
\text { Time frame: } 2010-2018 \\
\text { White areas: yes }\end{array}$ \\
\hline \multirow[t]{2}{*}{$\begin{array}{l}N Z \\
\ll 5\end{array}$} & $\begin{array}{l}\text { Government establishes PPPs at local levels in } \\
\text { connection with a tender procedure subject to } \\
\text { a vertical separation obligation } \\
\text { Total costs } € 1.6 \mathrm{~b} \\
\text { Public subsidies: (at least) } 50 \%\end{array}$ & $\begin{array}{l}\text { Up to } 100 \mathrm{Mbit} / \mathrm{s} \text { for } 75 \% \text { of population by } \\
2018 \\
\text { Time frame: } 2010-2018 \\
\text { White areas: yes }\end{array}$ \\
\hline & \multicolumn{2}{|l|}{ Source (AU; NZ): Given (2010, p. 544) } \\
\hline
\end{tabular}

\section{Linear profit-sharing contracts for subsidizing NGA networks in the presence of asymmetric information}

From the empirical evidence on the real-world contracts for NGA deployment projects

(Table 1), two features seem to emerge: First, all public authorities fix ex ante the level of NGA expansion and other quality parameters. One might infer from this practice that public authorities assume that they are well informed about the cost and demand parameters of NGA projects and thus they consider the inefficiency bias due to asymmetric information as negligible. This assumption might be justified in view of the cumulated experiences of the sector-specific regulation of first-generation infrastructure for more than a decade now. However, owing to the specific risks and uncertainties inherent in the migration towards second-generation NGA infrastructure and future broadband services, the validity of such a line of reasoning seems to be limited. Generally, regulators, let alone local and regional governments, always have less information than private firms about the benefits and costs of deploying and 
operating (NGA) networks, which gets reinforced in view of the current transitional process. In particular, there seems to be high information asymmetry about the level of total capital costs, i.e. capital expenditure (CAPEX) at the project start and during network expansion plus the cost of capital/required rate of return). Note that the risk premium to be included in the cost of capital depends on a multitude of uncertainties about wholesale and retail demand, cost conditions and technological progress and regulatory and market dynamics. (European Commission (2010b, Appendix, section 6). In particular, demand and willingness to pay for future NGA services seem to still be highly uncertain for potential investors, and even more so for public authorities, ${ }^{15}$ and demand uncertainty thus constitutes a major source of the overall risk associated with the NGA rollout (dot.econ, 2012, pp. 51-55). With increasing and non-systematic risks, investors will require a higher expected return, which increases the costs of capital. The latter, however, which is largely unknown by the public authority, is decisive for the optimal network size. A small change in the required return on capital for the NGA provider can have a significant impact on the decision of whether to build the network (wik consult, 2008, para 21).

Second, the implemented claw-back rules apply profit caps, which leave all downside risks to the NGA provider but limit its upside earning potential. This rule discriminates

15 See Weyl and Tirole (2012). The authors theoretically explore the best way to reward innovation by examining different mechanisms such as patent protection in order to determine consumers' willingness to pay for a certain project. In doing this, the authors also assume that firms are better informed about consumers' willingness to pay than the public authority. 
against riskier NGA projects that show more uncertain and variable returns but are nevertheless socially desirable. Furthermore, a benchmarking of realized profits compared with the industry average causes further verification costs and increases the regulatory risk for the NGA provider because it is uncertain about what future profits to expect.

In section 3.1, we set up the baseline model with complete information by the public authority about capital costs. In section 3.2, we construct the optimal linear contract under incomplete information about capital costs. Linear profit-sharing contracts are not only easy to implement but also considered to be especially robust and therefore suitable for situations that involve a high degree of uncertainty about future demand and costs. ${ }^{16}$ Furthermore, the linear sharing of realized earnings does not discriminate against riskier projects because the public authority not only receives a constant share of the NGA provider's profits but also participates in its losses in the same proportion.

\subsection{The baseline model with complete information}

We will analyze the public financing of an NGA network in a region where such a network would not be commercially viable (white area). The public authority has

16 Linear contracts are considered to be more "robust" compared with non-linear contracts. Caillaud et al. (1992) analyze the case when profits are influenced not only by the agent's decision but also by exogenous stochastic shocks. They show that the principal needs less information about the distribution of the exogenous shocks when using contracts that are linear in realized profits. Diamond (1998) shows that linear profit-sharing contracts achieve a higher level of welfare when the agent has to decide on more than one variable (e.g. the size and quality characteristics of an NGA network). 
nevertheless an interest to engage an NGA provider for its construction for the reasons outlined in section 2.2.

Let us assume that $e$ stands for the expansion level of the NGA network with $0 \leq e \leq 1$. If $e=0$, the NGA network will not be built at all and if $e=1$, the network covers the whole region. The marginal social surplus that can be achieved from each further unit of expansion is set to 1 . This surplus includes both the private users' utility and the positive external effects of the NGA rollout. To emphasize the importance of regional cohesion (digital divide), each marginal increase in network coverage has the same social value for the public authority.

The NGA provider expects to earn revenues $R(e)=(r+\varepsilon) e$ from private users. The expected marginal revenue $r$ is constant and $o<r<1$ but uncertain, where $\varepsilon$ is a random term with the expected value $E(\varepsilon)=o$. Future demand and revenues are uncertain because it is not known to which degree users will take up high-speed broadband services. The construction of the NGA network causes capital costs in the amount of $C(e)=\beta v(e)+\mu .{ }^{17}$ Assume that the capital cost parameter $\beta>0, \beta v(0)=0, \beta v^{\prime}(e)>0$, $\beta v^{\prime}(0)<1$ and $\beta v^{-\prime}(e)>0$. The random term $\mu$ with the expected value $E(\mu)=0$ represents exogenous cost risks that cannot be influenced by the NGA provider. The

${ }_{17}$ To simplify the model, operating expenditure (OPEX, such as administration, personnel, right-of-way costs, backhaul connection, network maintenance and troubleshooting or subscriber acquisition and marketing) are set to zero. It seems to be reasonable to assume that the public authorities should have good knowledge about the level of operating costs because those costs should not differ significantly between NGA providers. Furthermore, realized OPEX can be reliably verified from the NGA provider's cost accounts. 
capital costs include CAPEX as well as the required rate of return that the private investor expects from this project taking account of the demand and cost risks. ${ }^{18}$

Besides revenues from private users, the NGA provider will receive a public transfer $T$ to finance the capital costs that cannot be covered from these revenues. This gives the following profit function:

(1)

$$
U=R(e)+T-C(e)
$$

The public authority includes in its welfare function $W$ the benefits from NGA expansion $e$, the expected expenditure re from consumers as well as its own expenditure $T$. The welfare function does not include the NGA provider's profit $U$ because real-world regulators do not want to allow any excess profits for the NGA provider beyond a reimbursement of the incurred capital costs (see section 2.3). If the public authority had complete knowledge about the capital costs, the optimal levels of network expansion and transfer would be derived as follows subject to the constraint that the NGA provider has to expect a non-negative profit $U$ :

$$
\begin{aligned}
& \max _{e, T} W=e-r e-T \\
& \text { s.t. } T+r e-\beta v(e) \geq 0
\end{aligned}
$$

Accordingly, the necessary first-order condition for expansion is $\beta v^{\prime}(e)=1$. The marginal cost of network expansion must be equal to the marginal benefits of network expansion. Let $e^{\star}$ denote the solution to (2). The optimal transfer $T$ is then given by:

18 The required rate of return will depend on the refinancing costs of the NGA provider on the capital markets (e.g. evaluated based on the Capital Asset Pricing Model). 
(3)

$$
T=\beta v\left(e^{*}\right)-r e^{*}
$$

Thus, the NGA provider is only reimbursed its expected losses from the expansion $e^{\star}$ to minimize the burden on the public budget.

\subsection{Linear profit-sharing contract with incomplete information about capital costs}

The public authority and NGA provider sign a contract before the investment starts. The contract grants a subsidy that increases with the level of network expansion and imposes a sharing of the accounting profits that are realized by the NGA provider from the operation of the constructed NGA network. This means that the public authority receives a constant share of realized profits and takes up a similar share of realized losses.

In the contracting stage, the public authority has incomplete information about the NGA provider's capital costs $\beta v(e)$. Whereas $v(e)$ is assumed to be public knowledge, the public authority has no precise knowledge about the type parameter $\beta$ but only knows that the NGA provider is some type $\beta \in[\underline{\beta}, \bar{\beta}]$. The beliefs held by the public authority are described by the continuous distribution $F(\beta)$ with density $f(\beta)$ on the interval $[\underline{\beta}, \bar{\beta}]$ with $\underline{\beta}>0$ and $f(\beta)>0$ for all $\beta$. As is generally the case, the NGA provider's capital costs also cannot be verified based on the published accounts. Although certain capital cost items (e.g. amortization, depreciation, interest payments on loans) are recorded in the accounts, the required rate of return on equity is neither included in the accounts nor can it be verified in any other way (it remains private company information). Furthermore, as explained in more detail in section 4.2, 
depreciation and amortization costs are often prone to accounting manipulations. To make the contract robust against any accounting manipulations, the contract will only depend on the EBITDA (= earnings before interest, tax, depreciation and amortization) of the NGA provider, i.e. the operating profit as the difference between revenues and operating costs. The contract can therefore be implemented based on readily available and robust data (i.e. the level of network expansion $e$ and accounting profit EBITDA).

The public authority grants a subsidy of $(1-r)$, i.e. the expected difference between the marginal social surplus and marginal private revenue, for each further unit $e$ of network expansion. Thus, the NGA provider will earn - for a given expansion level of $e-$ a total income of $e(1+\varepsilon)$, that is the sum of the realized revenue $R(e)=(r+\varepsilon) e$ and of the public subsidy (1 - r)e. As operating costs are assumed to be zero, the accounting profit EBITDA will equal the total income of $e(1+\varepsilon)$. Based on the realized EBITDA, the NGA provider will have to pay taxes at a tax rate $t \in[0,1]$. Furthermore, the public authority imposes a lump-sum $\operatorname{tax} z$ on the NGA provider. Putting the public subsidy and tax payments together, the public authority offers the following linear contract $T(e)$ to the NGA provider:

(4) $T(e)=(1-r) e-t(1+\varepsilon) e-z$.

Under the given linear contract, the NGA provider has to solve the expansion level $e$ that maximizes its expected profit $U$ :

$$
\max _{e} U=E(T(e))+r e-\beta v(e)=(1-t) e-z-\beta v(e)
$$


The NGA provider will chose its optimal network expansion such that the marginal return after tax equals its marginal capital costs. The first-order condition is:

$$
(1-t)=\beta v^{\prime}(e)
$$

Given $v^{\prime \prime}(e)>0$, the second-order condition for maximization is fulfilled. ${ }^{19}$

Denote the solution to the above programme with $\hat{e}(t, \beta)$. By invoking the envelope theorem, the indirect profit function can thus be written as a function of the tax rate $t$ :

$$
\text { (7) } \quad \hat{U}(t, \beta)=\int_{0}^{1-t} \hat{e}(\tilde{t}, \beta) d(1-\tilde{t})-z
$$

Define a total surplus $S$ as the sum of the public authority's welfare $W$ and NGA provider's profit $U$. The surplus $S$ is then given by the function:

$$
\hat{S}(t, \beta)=\hat{e}(t, \beta)-\beta v(\hat{e}(t, \beta))
$$

As Lemma 1 shows, the tax rate $t$ controls the expansion of the network. The lower the tax rate, the higher is the NGA network expansion $e$. With a tax rate $t=0$, the NGA provider is the residual claimant of any surplus and will therefore provide the first-best expansion level $e^{*}$ as under complete information. ${ }^{20}$ With $0<t<1$, the NGA provider receives a positive and constant fraction of any surplus from the network expansion.

19 As explained in section 3.1, the behaviour of the NGA provider is independent of the demand uncertainty term $\varepsilon$ and cost uncertainty term $\mu$ under a linear contract. Knowledge of the distribution of $\varepsilon$ and $\mu$ is therefore not necessary to predict the behaviour of the NGA provider.

20 It follows therefore from Lemma 1 that the optimal expansion level $e^{\star}$ can be implemented under incomplete information as long as the public authority is ready to leave a positive level of expected profit $U$ to the NGA provider. 
Based on the tax rate $t$, the realized profit is shared ex post between the public authority and NGA provider. With a tax rate $t=1$, the NGA provider does not participate in the surplus and will thus not invest in the network. Contrary to an ex ante mandated network size by the public authority, the NGA provider will optimally adjust the expansion level $e$ to its capital costs. As shown in Lemma 1, a more efficient NGA provider will expand further and achieve a higher rent as well as a higher surplus for any given tax rate $t<1$

Lemma 1: Given $1-t>0$, the optimal expansion $\hat{e}(t, \beta)$, the profit $\hat{U}(t, \beta)$ as well as the surplus $\hat{S}(t, \beta)$ decrease in the tax rate $t$ and the type $\beta$.

Proof: See Appendix.

The NGA provider will only enter into the contract given that it receives a non-negative profit $\hat{U}(t, \beta) \geq 0$. Lemma 1 showed that for a given contract, a more efficient type achieves a higher rent. Given that the marginal surplus of network expansion is positive at $e=o$, even for the most inefficient type of NGA provider (i.e. $1-\bar{\beta} v^{\prime}(0)>0$ ), the public authority wants to undertake network expansion in any case. Thus, the individual rationality constraint $\hat{U}(t, \beta) \geq 0$ can only be binding for type $\bar{\beta}$. Denote the optimal expansion of the most inefficient type with $\bar{e}(t)=e(t, \bar{\beta})$. The lump-sum $\operatorname{tax} z^{*}$ is therefore set in such a way that no rent is left to the most inefficient type, i. e. $\hat{U}(t, \bar{\beta})=0$ , which gives - using the utility function (7) - the optimal lump-sum tax:

(9)

$$
Z^{*}=\int_{0}^{1-t} \bar{e}(\tilde{t}) d(1-\tilde{t})
$$


With hidden cost information, the entire rent can thus only be extracted from the most inefficient type. All other types will enjoy a positive rent. The difference $\hat{U}(t, \beta)-\hat{U}(t, \bar{\beta})(=\hat{U}(t, \beta))$ for $\beta<\bar{\beta}$ is commonly called information rent. The information rent of any type $\beta$ can now be written - substituting the optimal lump-sum $\operatorname{tax}(9)$ into (7) - as:

$$
\hat{U}(t, \beta)=\int_{0}^{1-t} \hat{e}(\tilde{t}, \beta) d(1-\tilde{t})-\int_{0}^{1-t} \bar{e}(\tilde{t}) d(1-\tilde{t})
$$

To find the optimal tax rate $t^{*}$, the public authority has to maximize the expected value of its welfare function ((2) and using (8)) over all types of $\beta$ :

$$
\max _{t} \int_{\underline{\beta}}^{\bar{\beta}}[\hat{S}(t, \beta)-\hat{U}(t, \beta)] d F(\beta)
$$

By using (6), (8) and (10) and defining the expected network expansion as $\tilde{e}=\int_{\underline{\beta}}^{\bar{\beta}} \hat{e}(t, \beta) d F(\beta)$ and the expected marginal tax reaction as $\tilde{e}_{t}=\int_{\underline{\beta}}^{\bar{\beta}} \frac{\partial \hat{e}(t, \beta)}{\partial t} d F(\beta)$, the first-order condition can be expressed as:

$$
-t \tilde{e}_{t}=(\tilde{e}-\bar{e})
$$

Accordingly, the optimal tax rate must be set such that the NGA provider chooses an expansion level at which the expected marginal gain in rent extraction $(\tilde{e}-\bar{e})$ is equal to the expected marginal loss in surplus $\left(-t \tilde{e}_{t}\right)$ from a further increase in network size. If the public authority does not know the efficiency parameter $B$, it will trade off the gains from a further expansion against the extraction of information rent. Figure 1.a shows the lump-sum tax $z^{\star}$ (area $A$ ) and tax payment tê that a type $B$ will pay (area $B$ ). 
Remember that the lump-sum tax is optimally chosen such that when the NGA provider is of type $\bar{\beta}$, it will earn no rent. The public authority will be able to extract more rent in the approximate magnitude of $(\hat{e}-\bar{e}) \Delta t$ from a type $\beta<\bar{\beta}$ if the tax rate is increased by $\Delta t$. See area (1) in Figure 1.b for the marginal gain in rent extraction for a single type $\beta<\bar{\beta}$. However, the public authority also loses surplus from the decreased network expansion in the approximate magnitude of $-t \hat{e}_{t} \Delta t$. See area (2) in Figure 1.b for the loss in efficiency for a single type $\beta<\bar{\beta}$.

In the next proposition, it is shown that the optimal tax rate must lie between 0 and 1 . This states that a necessary condition for optimality is that ex post profit sharing takes place. It is optimal to sacrifice network expansion for the reduction of information rent. Under the optimal linear contract, any type - except the most inefficient one - will enjoy a positive rent $U$. Any type will build a smaller network than the first-best expansion $e^{\star}(B)$.

Proposition 1: The optimal tax rate satisfies $1>t^{\star}>0$.

Proof: See Appendix. 


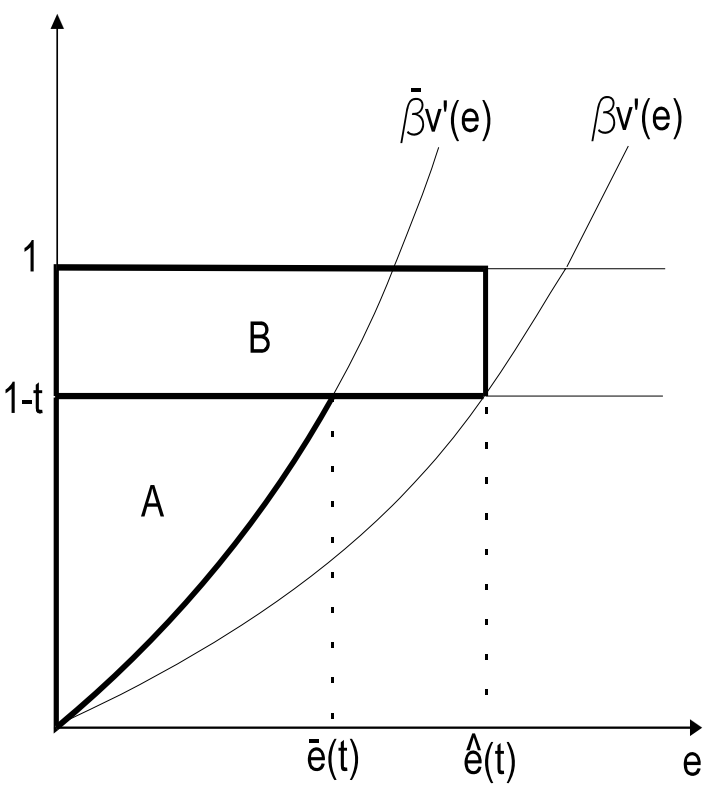

Figure 1.a: Tax payments for type $\beta$

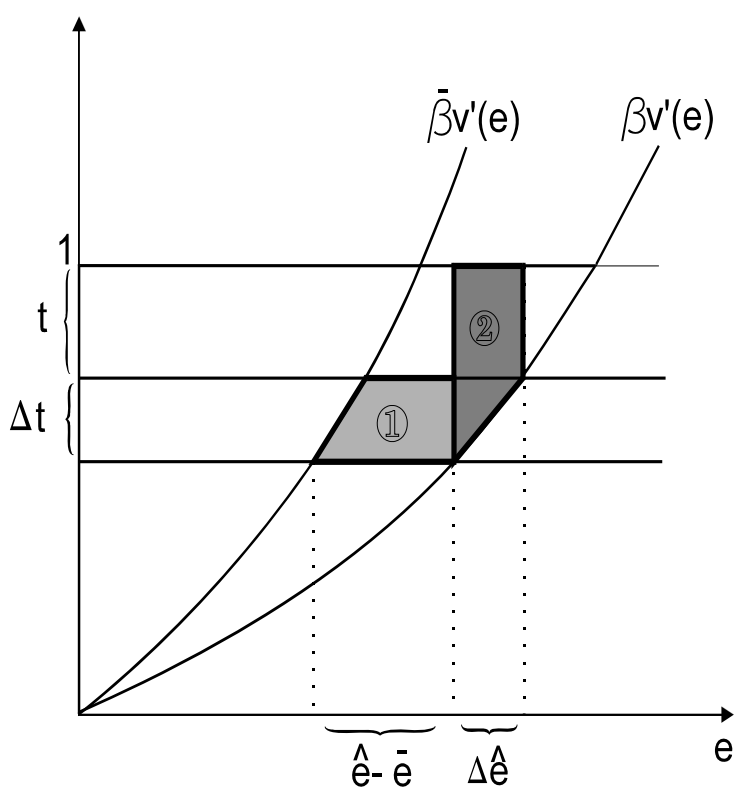

Figure 1.b: Effects of tax rate change for type $B$

It is important to highlight that the optimal tax rate $t^{\star}$ depends sensitively on the public authority's beliefs about the parameter $\mathcal{B}$. Depending on the characteristics on the belief distribution $F(B)$, it will often be the case that higher uncertainty about the capital costs will lead to a higher tax rate because the gains from rent extraction will outweigh more easily the losses from a smaller network size. If the public authority has more precise knowledge about the capital costs, the tax rate $t$ will be set at a lower level and the lump-sum tax $z$ can be used to extract the NGA provider's rent. ${ }^{21}$

${ }_{21}$ When setting the optimal tax rate in practice, it must be taken into account that the NGA provider will already be subject to corporate tax. For example, if the NGA project-specific optimal tax rate $t^{\star}$ was lower than the general corporate tax rate $t$, it would effectively be necessary for the public authority to pay a marginal subsidy $t^{*}$ - $t$ for each further percentage of network expansion to reach the optimal network size. 


\section{Main results and policy implications}

The results of the theoretical model call for three immediate changes in the practical design of contracts for the public financing of NGA networks.

\subsection{Endogenous determination of NGA coverage and quality characteristics}

As the empirical evidence in section 2.3 showed, public authorities typically predefine the relevant quality parameters of network expansion. However, such a top-down approach is not efficient in the presence of asymmetric information about NGA deployment costs. The theoretical analysis showed that the optimal contract delegates the decision concerning the expansion level $e^{22}$ to the much better informed NGA provider. Public authorities must therefore refrain from determining themselves the size and quality characteristics of NGA networks but rather design a contract that contains the appropriate incentives for the provider to optimally deploy the NGA network with regard to its social benefits and costs. The NGA provider must have the flexibility to determine the network size based on its superior cost information and it must be accordingly rewarded for its performance.

\subsection{Linear profit sharing as a simple and robust claw-back mechanism}

The public authority is confronted with a trade-off between maximizing network coverage and minimizing total NGA project costs as well as the profits of the provider. To save public funds, it is recommendable to share the realized profits ex post such

22 The decision variable $e$ could equally be interpreted as the NGA network's bandwidth level (Mbit/s). Thus, the public authority would design a contract to leave the NGA provider the choice between the different quality levels in terms of bandwidth technologies $(\mathrm{FTTC} / \mathrm{B} / \mathrm{H})$. 
that the agent is also the residual claimant of the overall profitability of the project. In this respect, linear profit-sharing contracts seem to be particularly attractive because they are easily implementable at low information requirements.

Real-world examples of claw-back mechanisms (as cited in footnote 14) are complex because they will only kick in if the provider realizes high profits because of, say, higher than expected demand or better performance than the industry average. Thus, the public authority has to monitor ex post the realization of several variables and calculate the amount of profit that is deemed to be "excessive". In practice, it will not be easy to verify ex post whether the provider has performed better or worse than the industry average. Such ex post benchmarking will at least incur costs for expert studies or lead to lengthy legal proceedings subject to a high degree of asymmetric information and unpredictable decisions.

On the contrary, the proposed linear profit sharing can be easily implemented. The tax payment only depends on the EBITDA that the NGA provider records in its accounts. As the tax payment is a constant share of the realized profit, the public authority does not need to monitor any further exogenous variables (e.g. demand growth, cost trends and industry-average profitability) to determine when profit sharing must kick in as with the non-linear claw-back rules (footnote 14$)$.

Moreover, as a linear sharing rule does not put an absolute cap on realized profit, the NGA provider will always earn an additional profit from further investment. The linear sharing rule offers better incentives and the NGA provider has more certainty about the level of realized profit that it can expect. The emphasis on absolute caps for realized 
profits by real-world regulators (e.g. European Commission, 2013, para 79 i) therefore seems to be misplaced because it only generates verification costs and increases the regulatory risk for the NGA provider.

Finally, with a view to having a robust accounting measure for realized profit, the contract has been based on the EBITDA. Contrary to the EBIT (= earnings before interest and tax), it is less prone to accounting manipulations because the public authority does not need to verify whether amortization and depreciation costs were correctly recorded in the accounts. For example, an NGA provider that has vertically split its operations (e.g. network construction business, wholesale operations and retailing) into separate legal entities would be able to shift amortization and depreciation costs between those entities by manipulating the transfer prices between them. If the EBIT were used as a tax base, the public authority would need to additionally monitor those transfer prices to verify that the recorded EBIT took proper account of amortization and depreciation costs. ${ }^{23}$

Furthermore, as profit sharing is based on the EBITDA, the NGA provider remains the residual claimant of any savings in capital costs and has no incentive to decrease its efforts to control those costs.

${ }_{23}$ If amortization and depreciation expenses were verifiable accounting costs (e.g. the NGA provider could not hide profits by invoicing higher than actually incurred (APEX), tax could also be based on the EBIT. In this case, let $v(e)$ denote the publicly known amortization and depreciation costs and $\gamma$ the rate of return on which the public authority has ex ante incomplete information. The profit function (5) would then read as follows: $U(e)=(1-t)(e-v(e))-z-\gamma v(e)$. 


\subsection{Menu of linear profit-sharing contracts at low information costs}

The public authority will achieve a Pareto improvement if it offers an additional linear profit-sharing contract - which has a higher lump-sum fee and a lower tax rate than the original contract - to the NGA provider. Both the public authority and the NGA provider will be better off if the NGA provider chooses the additional option because of a reduction in the transfer $T$ and an increase in the NGA provider's profit $U$. Similar to the literature on non-linear pricing, this menu will be called a Pareto-dominating menu of contracts (Brown \& Sibley, 1986, chapter 4).24

Note that the information requirements for the design of a Pareto-dominating menu of contracts are very low. A Pareto-dominating menu can be constructed based only on the public authority's belief about the expansion level of the most efficient type under the first contract. There is no need for further information about the properties of the capital cost function $\beta v(e)$. The information requirements are thus much less demanding than those for the design of an optimal single linear contract under asymmetric information.

Lastly, to reduce information rent even further, the public authority could organize a tender. The considerations on linear profit sharing can be fully carried over to the

24 See Laffont and Tirole (1993) for the design of an optimal linear contract menu in a different regulatory setting. Miravete (2007) shows that depending on the shape of the distribution function $F(\beta)$, a linear contract or a simple menu with two options can achieve a significant share of information rent (e.g. above 90\%) for the public authority. Adding more options to the menu will only yield minor additional gains. 
design of auctions: the public authority will not simply ask the bidders for the lowest subsidy but choose from a menu of linear contracts with different pairs of marginal subsidies $(1-t)$ and average transfer payments $(T / e)$. To win the tender, the most efficient NGA provider will choose the contract with the highest marginal return $(1-t)$ in exchange for the lowest average transfer payments ( $T / e)$.

\section{Further policy considerations}

The foregoing section presented the advantages that directly follow from the proposed NGA subsidy scheme. This section analyzes the scheme with regard to further criteria and discusses possible reasons against the use of linear profit sharing.

\subsection{Risk allocation}

In the case that NGA providers are risk-averse, it would be useful to compare the position of a provider in a black area without any subsidy with that of a provider in a white area who benefits from the proposed NGA subsidy scheme. NGA providers in black areas assume all exogenous demand and cost shocks. To achieve investment neutrality and a level playing field between the two areas, a risk-averse NGA provider in a white area should not benefit from a more favourable risk allocation compared with NGA providers in a black area.

The realized profits of an operator in a black area will be subject to the general corporate tax. The proposed profit-sharing contract can be expressed as a supplement to or a deduction from the corporate tax. If $t^{*}>$ tcorp, the provider will have to pay an additional tax $t^{\star}$ - torp on realized profits or will receive a respective subsidy on losses 
compared with the general corporate tax to which a provider in a black area is subject. ${ }^{25}$

In the case of $t^{*}>$ torp, the proposed NGA subsidy scheme provides an additional hedging of downward risk, which may be appealing to risk-averse providers. However, public authorities may dislike these additional loss coverage through public funds - in particular with $t^{*}$ significantly higher than $t^{c o r p}$ - in times of scarce public funds. The NGA provider would also have to pay an appropriate risk premium to the public authority.

A full analysis of risk allocation would need to take account of the risk preferences of the NGA provider and public authority (e.g. a budget-constrained local public authority may be more risk-averse than a private NGA provider) as well as the differences in exogenous demand and costs risks between black and white areas.

\subsection{Incentives for moral hazard by the NGA provider}

To discuss incentives for moral hazard, it should be recalled that profit sharing is based on the realized EBITDA. This means that while increases in accounted operating

25 For the definition of $t^{\text {torp }}$, it must be taken into account that the corporate tax rate is calculated based on the EBIT and not the EBITDA and a comparison must be made with regard to the same tax base. Furthermore, with regard to the treatment of losses in the general corporate tax, these losses will only reduce the tax burden in later periods when profits will again be earned and the carried-forward losses can be deducted from the tax bill. The implicit subsidy may therefore be higher depending on the interest rate and possibility of fully offsetting losses against future profits. 
costs will reduce the EBITDA, increases in accounted capital costs will leave the EBITDA unchanged.

If $t^{*}$ is unequal to $t^{\text {corp}}$, an NGA provider that operates in both white and black areas will have an incentive to shift overhead costs for the operations of NGA networks to the area with the effectively lower tax rate. Additional verifications of accounts may therefore become necessary but it should be difficult to justify differing allocations of operating costs. However, some additional verification costs may be necessary compared with a subsidy scheme without profit sharing.

With regard to capital costs, it has already been explained in section 4.2 that the provider will have no incentive to inflate capital costs through accounting manipulations or cost overruns because profit sharing is based on the EBITDA. ${ }^{26}$

\subsection{Political economy}

The main benefit of the proposed NGA subsidy scheme lies in its higher efficiency with regard to the use of public funds. However, in the case that subsidies are managed at local and regional levels but co-financed by national or supra-national funds, local politicians may have an incentive to argue for an ex-ante fixed rollout target and be less concerned about savings in public funds. As savings in public funds will benefit not only the local budget but also the regional or national budgets, such savings may be of less concern to the local electorate. In addition, there could be an aspect of a subsidy race between the different regions, which may trump the savings in public funds. The

${ }_{26}$ Only in the case that $t^{*}<$ torp would the NGA provider have an incentive to shift costs from white area to black area accounts. 
local electorate may respect that more public funds have been secured for their region. Finally, a fixed target promising high-speed broadband for all areas and households is much more attractive to communicate than contracts based on more subtle efficiency considerations. This also allows clear communication to the local electorate and enables local politicians to show that they have fulfilled their promised targets.

\section{Summary and final remarks}

Our analysis, which connects recent studies of public financing and investment of new communications infrastructure with the traditional literature on regulatory theory under asymmetric information, presented in detail the inefficiencies involved in the previous practice of NGA subsidy programmes. The analysis indicates that these inefficiencies will depend on the extent of asymmetric information. Compared with simple linear profit-sharing contracts, it is not optimal that the public authority mandates an NGA deployment project of a certain size or quality given its asymmetric information on capital costs. However, it must be noted that the European Commission (2012) now puts more emphasis on efficiency incentives for public service contracts, as in its new Framework on state aid for the compensation for public service obligations, it requires that public authorities include efficiency incentives when granting state aid to large public service providers. The proposed linear profit-sharing contracts are good examples of how to put better efficiency incentives into practice but at the same time still limit the burden on the public budget. It should be hoped that more innovative contracts will accordingly be implemented. 
This analysis was subject to the basic premise that public subsidies for NGA deployment are necessary and socially desirable. However, funding and cooperation has become more complex in the case of second-generation networks, as any subsidies also involve the risk of distorting already established competitive market developments based on first-generation infrastructure as well as ex ante investment incentives. Public funds should crowd in but not crowd out any private NGA investment. Accordingly, public subsidies should not be on the funding agenda for black areas. For grey areas, with one network already in place, government intervention should be feasible only in exceptional cases, since there is a high risk of market distortions in such situations (European Commission, 2013).

Given these warnings in terms of the relevant safeguards for competition and in view of the basic result of our analysis and the related theoretical literature Jullien et al., 2010), one should opt for a narrowly defined role for governments in subsidizing NGA projects. The efficient amount of government intervention should be determined endogenously in response to actual costs and demand and be restricted to white areas only. 


\section{Appendix}

Proof of Lemma 1: The first-order condition (6) evaluated at the optimal expansion $\hat{e}(t, \beta)$ and differentiated with respect to $\operatorname{tgives}-1-\beta v^{\prime \prime}(.) \frac{\hat{\partial e}}{\partial t} \equiv 0$.

From this, it follows that $\frac{\hat{\partial}}{\partial t}<0$. Differentiating $\hat{U}(t, \beta)=\int_{0}^{1-t} \hat{e}(\tilde{t}, \beta) d(1-\tilde{t})-z$ with respect to $t$ gives $\frac{\partial \hat{U}}{\partial t}=-\hat{e}(t, \beta) \leq 0$. Differentiating $\hat{S}(t, \beta)=\hat{e}(t, \beta)-v(\hat{e}(t, \beta))$ with respect to $\operatorname{tgives} \frac{\partial \hat{S}}{\partial t}=\left(1-\beta v^{\prime}\right) \frac{\hat{\partial}}{\partial t} \leq 0$.

This is because from the first-order condition the marginal costs of expansion $\beta v^{\prime}(\hat{e}()$. are equal to $(1-t) \leq 1$. The proof is similar for the comparative statics in relation to type $\beta$.Q.E.D.

Proof of Proposition 1: By using (8) and (10), (11) can be rewritten as

$$
\max _{t} \omega=\int_{\underline{\beta}}^{\bar{\beta}}\left[(\hat{e}(t, \beta)-\beta v(\hat{e}(t, \beta)))-\left(\int_{0}^{1-t} \hat{e}(\tilde{t}, \beta) d(1-\tilde{t})-\int_{0}^{1-t} \bar{e}(\tilde{t}) d(1-\tilde{t})\right)\right] d F(\beta)
$$

The first-order condition with respect to the tax rate reads as follows, using $(1-t)=\beta v^{\prime}(e)$ from $(6)$ :

(14)

$$
\int_{\underline{\beta}}^{\bar{\beta}}\left[t \frac{\partial \hat{e}}{\partial t}+(\hat{e}-\bar{e})\right] d F(\beta)=0
$$


(a) With $t=1$, the NGA provider will not build any network. The value of the welfare function $\omega=\int_{\underline{\beta}}^{\bar{\beta}}[\hat{S}(1, \beta)-\hat{U}(1, \beta)] d F(\beta)$ thus equals zero. With any tax rate $1>t \geq 0$, welfare $\omega$ is greater than zero.

(b) By using the definitions for average network expansion and marginal tax reaction, (14) simplifies to (12). Evaluated at $t=0$, the derivative $\left.\frac{d \omega}{d t}\right|_{t=0}=(\tilde{e}-\bar{e})>0$. Average expansion is greater than the expansion by the most inefficient type because $\frac{\partial \hat{e}}{\partial \beta}<0$ from Lemma 1. Q.E.D.

Proof of Proposition 2: (a) It is established that there exist types $\beta$ who accept the contract $T_{2}(e)$. A type $\beta$ will choose contract $T_{2}(e)$ given that $\hat{U}\left(T_{2}, \beta\right)-\hat{U}\left(T_{1}, \beta\right) \geq 0$. This is equivalent to writing that the change in the profit resulting from the change in the tax rate must be at least equal to the change in the lump-sum tax, $\int_{1-t_{1}}^{1-t_{2}} \hat{e}(\tilde{t}, \beta) d(1-\tilde{t}) \geq\left(t_{1}-t_{2}\right) \underline{e}_{1}$.

For the most efficient type, the left-hand side is strictly greater than the right-hand side. The right-hand side is positive because it represents the change in the utility resulting from the change in the tax rate for $\underline{e}_{1}$ units of expansion. From Lemma 1 , it is known that the rent is decreasing in the tax rate. Therefore, the left-hand side is also positive. Furthermore, it is known from Lemma 1 that the NGA provider will supply a higher expansion at the lower tax rate $t_{2}$. Remember that by definition the NGA provider's expansion efforts with the higher tax rate $t_{1}$ is equal to the expansion level $\underline{e}_{1}$. The left- 
hand side is therefore greater than the right-hand side by the surplus achieved by the higher network expansion with the contract $T_{2}(e)$ than $\underline{e}_{1}$ units with the contract $T_{1}(e)$.

(b) It is now shown that the contract $T_{2}(e)$ leads to a reduced amount of $T$. Let $\hat{e}_{i}$ and $T_{i}$ denote the expansion level and transfer under the respective contract $i$. It must be that $T_{1}>T_{2}$, which is equivalent to $\left(t_{1}-t_{2}\right) \underline{e}_{1}>t_{1} \hat{e}_{1}-t_{2} \hat{e}_{2}$.

This expression is fulfilled as long as the tax imposed on the network expansion increases or at least does not decrease by more than the increase in the lump-sum fee $z$. The foregoing expression can be rearranged - by using $\hat{e}_{2}=\hat{e}_{1}+\left(\hat{e}_{2}-\hat{e}_{1}\right)-$ to $-\left(t_{1}-t_{2}\right)\left(\underline{e}_{1}-\hat{e}_{1}\right)<t_{2}\left(\hat{e}_{2}-\hat{e}_{1}\right)$.

As it is known from Lemma 1 that $\frac{\hat{d}}{\partial t}<0$, it follows that the right-hand side is positive. The left-hand side is zero for the most efficient type because of the definition $\underline{e}_{1} \equiv \hat{e}\left(t_{1}, \underline{\beta}\right)$. It is negative for any other type because $\frac{\partial \hat{e}}{\partial \beta}<0$ as known from Lemma 1. Q.E.D. 


\section{References}

Analysys Mason (2008), The Costs of Deploying Fibre-Based Next-Generation Infrastructure, Final Report (12726-371), Available from http://www.ictregulationtoolkit.org/en/Publication.3971.html.

Armstrong, M. \& D. Sappington (2007), Recent Developments in the Theory of Regulation, in: Armstrong, M. \& R.H. Porter (Eds.), Handbook of Industrial Organization, Amsterdam.

Armstrong, M. \& D. Sappington (2006), Regulation, Competition and Liberalization, Journal of Economic Literature 44, 325-366.

Bauer, J.M. (2010), Regulation, Public Policy, and Investment in Communications Infrastructure, Telecommunications Policy 34, 65-79.

Belloc, F., Nicita, A., \& M.A. Rossi (2012), Whither Policy Design for Broadband Penetration? Evidence from 30 OECD Countries, Telecommunications Policy 36, $382-398$.

Briglauer, W. (2014), The Impact of Regulation and Competition on the Adoption of Fiber-Based Broadband Services: Recent Evidence from the European Member States, Journal of Regulatory Economics (forthcoming).

Briglauer, W., Ecker, G. \& K. Gugler (2013), The Impact of Infrastructure and ServiceBased Competition on the Deployment of Next Generation Access Networks: Recent Evidence from the European Member States, Information Economics and Policy 25, 142-153.

Brown, S. \& D. Sibley (1986), The Theory of Public Utility Pricing, Cambridge. 
Caillaud, R., Guesnerie, R. \& P. Rey (1992), Noisy Observation in Adverse Selection Models, Review of Economic Studies 59, 595-615.

Cambini, C. \& Y. Jiang (2009), Broadband Investment and Regulation: A Literature Review, Telecommunications Policy33, 559-574.

Cave, M. \& I. Martin (2010), Motives and Means for Public Investment in Nationwide Next Generation Networks, Telecommunications Policy34, 505-512.

Czernich, N., Falck, O., Kretschmer, T. \& L. Woessmann (2011), Broadband Infrastructure and Economic Growth, Economic Journal121, 505-532.

Diamond, P. (1998), Managerial Incentives: On the Near Linearity of Optimal Compensation, Journal of Political Economy106, 931-957.

Doose, A.M., Elixmann, D. \& S. Jay (2009), Breitband/Bandbreite für Alle: Kosten und Finanzierung einer Nationalen Infrastruktur, wik-Discussion Paper 330, Bad Honnef.

dot.econ (2012), Regulatory Policy and the Roll-out of Fibre-to-the-Home Networks, Report Prepared for the FTTH Council Europe, London, Available from http://www.dotecon.com/news/fibre-to-the-home-council-europe-publishesdotecon-report/.

Engel, E., Fischer, R. \& A. Galetovic (2013), The Basic Public Finance of Public-Private Partnerships, Journal of the European Economic Association 11, 83-111.

Engel, E., Fischer, R. \& A. Galetovic (2001), Least-Present-Value-of-Revenue Auctions and Highway Franchising, Journal of Political Economy109, 993-1020. 
European Commission (2013), EU Guidelines for the Application of State Aid Rules in Relation to the Rapid Deployment of Broadband Networks, Official Journal C/25/2013, Brussels.

European Commission (2012), Commission Framework on Compensation for Public Service Obligations, C/8/2012, Brussels.

European Commission (2011), State Aid: Commission Approves Record Amount of State Aid for the Deployment of Broadband Networks in 2010, Press Release IP/11/54, Brussels.

European Commission (2010a), Europe 2020: A Strategy for Smart, Sustainable and Inclusive Growth, COM (2010)2020, Brussels.

European Commission (2010b), European Commission Recommendation on Regulated Access to Next Generation Access Networks, September 2010, Brussels.

European Commission (2010c), State Aid N 53/2010 - Germany - Federal Framework Program on Duct Support, Official Journal C/242/2010, Brussels.

European Commission (2010d). State Aid N 559/2009 - United Kingdom - North Yorkshire - Next Generation Broadband, Official Journal C/316/2010, Brussels. European Commission (2009), Community Guidelines for the Application of State Aid Rules in Relation to Rapid Deployment of Broadband Networks, COM (2009) 235/04, Brussels.

European Regulators Group (2007), Opinion on Regulatory Principles of NGA, Brussels, 16rev2, Available from http://erg.ec.europa.eu/doc/publications/ergo7_16rev2_opinion_on_nga.pdf. 
Falch, M. \& A. Henten (2010), Public Private Partnerships as a Tool for Stimulating Investments in Broadband, Telecommunications Policy34, 496-504.

FTTH Council Europe (2012a), Annual Report: April 2011 - April 2012, Available from http://www.ftthcouncil.eu/documents/Reports/FTTHCE_AnnualReport_20112012.pdf.

FTH Council Europe (2012b), Creating a Brighter Future - FTTH Global Ranking, $\begin{array}{llll}\text { Presentations } & \text { and } & \text { Reports, from }\end{array}$ http://www.ftthcouncil.eu/resources?category_id=7.

Garbacz, C. \& H. Thompson Jr. (2007), Mobile, Fixed Line and Internet Service Effects on Global Productive Efficiency, Information Economics and Policy19, 189-214.

Given, J. (2010), Take Your Partners: Public Private Interplay in Australian and New Zealand plans for Next Generation Broadband, Telecommunications Policy 34, $540-549$.

Gomez-Barroso, J. L. \& C. Feijob (2010), A Conceptual Framework for Public-Private Interplay in the Telecommunications Sector, Telecommunications Policy 34, 487495.

Holzleitner, C. (2001), Evolution of Regulatory Contracts - a Change for the Good? IFO Studien 47, 365-385.

Huigen, J. \& M. Cave (2008), Regulation and the Promotion of Investment in Next Generation Networks - A European Dilemma, Telecommunications Policy32, 713721. 
Iossa, E. \& D. Martimort (2008), The Simple Microeconomics of Public-Private Partnerships, Working Paper, University of Toulouse.

ITU - International Telecommunications Union (2009), Developments of Next Generation Networks (NGN): Country Case Studies, Geneva.

Jullien, B., Pouyet, J. \& W. Sand-Zantman (2010), Public and Private Investments in Regulated Network Industries: Coordination and Competition Issues, Review of Network Economics 9, Art. 3.

Laffont, J.J. \& J. Tirole (1993), A Theory of Incentives in Procurement and Regulation, Cambridge.

Martimort, D. \& J. Pouyet (2008), To Build or not to Build: Normative and Positive Theories of Private-Public Partnerships, International Journal of Industrial Organization 26, 393-411.

Miravete, E. (2007), The Limited Gains from Complex Tariffs, CEPR Discussion Paper No. 4235.

Neumann, K.H. (2010), Structural Models for NBN Deployment, wik Discussion Papers 342, Bad Honnef.

OECD (2009), Network Developments in Support of Innovation and User Needs, DSTI/ICCP/CISP(2009)2/FINAL, December.

OECD (2008), Developments in Fibre Technologies and Investment, DSTI/ICCP/CISP(2007)4/Final, April. 
Röller, L.H. \& L. Waverman (2001), Telecommunications Infrastructure and Economic Development: A Simultaneous Approach, American Economic Review 91, 909923.

RTR - Austrian Regulatory Authority for Broadcasting and Telecommunications (2010), Communications Report 2009, Vienna, Available from http://www.rtr.at/de/komp/alleBerichte.

Tirole, J. \& E.G. Weyl (2012), Market Power Screens Willingness-to-Pay, The Quarterly Journal of Economics 127, 1971-2003.

Ventura Team \& Portland Advisers (2012), Financing Stimulus for FTTH, Report Prepared for $\quad$ Council Europe, Available from http://www.ftthcouncil.eu/documents/Reports/FTTH_-Finance_Report.pdf. wik consult (2012), NGA Progress Report, Report Commissioned by ECTA, Bad Honnef. wik consult (2008), The Economics of Next Generation Networks, Report Commissioned by ECTA, Bad Honnef. 